\title{
Breast Cancer Awareness among Egyptian Women and the Impact of Caring for Patients with Breast Cancer on Family Caregivers' Knowledge and Behaviour
}

\author{
Ahmed H. Abdelaziz 1, 2, May A. Shawki ${ }^{3}$, Amrou M. Shaaban 4, Sali K. \\ Albarouki ${ }^{5}$, Ahmad M. Rachid ${ }^{5}$, Obai M. Alsalhani ${ }^{5}$, Mona K. Jomaa ${ }^{1}$
}

1 Clinical Oncology Department, Faculty of Medicine, Ain Shams University, Cairo, Egypt; ${ }^{2}$ Baheya Foundation for Breast Cancer, Giza, Egypt; ${ }^{3}$ Clinical Pharmacy Department, Faculty of Pharmacy, Ain Shams University, Cairo, Egypt; ${ }^{4}$ Clinical Oncology Department, Faculty of Medicine, Minia University, Minia, Egypt; ${ }^{5}$ Ain Shams University Hospitals, Cairo, Egypt

\begin{abstract}
Background: Breast cancer is the most common cancer in Egyptian females. Most patients present at a late stage with subsequent poor outcomes.

Aim: To study the awareness of breast cancer, its risk factors and screening. To investigate the impact of caring for a family member with breast cancer on the awareness and future attitudes of caregivers.

Methods: The study included 704 females divided into two groups. A non-caregivers group including 248 participants representing the general population and a caregivers group including 456 family caregivers of breast cancer patients. We used a questionnaire comprised of 45 questions assessing four domains: individual risk factors, awareness of risk factors, awareness of screening, and the practice of and barriers to screening. Those who answered more than $50 \%$ of the questions correctly were considered to have good knowledge.

Results: Sixty-nine percent of participants showed poor knowledge of risk factors. In the screening awareness domain, only $44 \%$ of participants scored $>50 \%$ indicating defective knowledge. Caregivers attained significantly higher scores in all domains $(p<0.001)$. Yet, the overall assessment showed poor knowledge in both groups. Only $3 \%$ of non-caregivers and $19 \%$ of caregivers performed mammography $(p<0.001)$; while $11 \%$ and $38 \%$, respectively, underwent breast self-examination $(p<0.001)$. Higher education level was associated with significantly better knowledge $(p<0.001)$.

Conclusions: Breast cancer knowledge among Egyptian females is deficient. The level of education and caring for a breast cancer patient significantly affect the level of knowledge and attitude towards screening. There is a need to implement a comprehensive national awareness and screening programme.
\end{abstract}

Keywords: Awareness, Breast cancer, Family caregivers, Egypt, Screening Corresponding Author: Ahmed H. Abdelaziz, MD; Clinical Oncology Department, Faculty of Medicine, Ain Shams University, Abbasseya Square, 11511, Cairo, Egypt; Email: ahmedabdelaziz@doctors.org.uk

Submitted: 9-September-2020, Finally revised: 5-November-2020, Accepted: 8-November-2020, Published online: 22November-2020

(cc) BY

\section{Introduction}

Breast cancer is the most common type of cancer in women and the first cause of cancer death among them ${ }^{1}$. In Egypt, it constitutes $33 \%$ of female cancer cases and more than 22,000 new cases diagnosed each year ${ }^{2}$. This is expected to rise exponentially over the next years given the enlarging population, changes in the population pyramid and adopting the westernized lifestyle. Despite significant improvements in survival figures in many developed countries yet the 5-year survival in Egypt as reported in several studies remained lower ranging from $28 \%$ to $68 \%{ }^{3,4}$. Multiple factors contribute to the lower survival outcomes and it is believed most patients are being diagnosed at late stages ${ }^{5}$.

A study by the Egyptian Ministry of Health and the Demographic and Health Survey project 
showed that only $2 \%$ of the surveyed Egyptian women had some form of clinical screening (mammogram, ultrasound or clinical breast examination [CBE]) and only 6\% performed breast self-examination (BSE) in the year prior to the survey ${ }^{6}$. This could be due to a medley of factors, some of which can be put down to the service provider (i.e. health care systems) while other factors are related to patients including social, cultural, financial and fear of the disease but it is believed that one of the main factors keeping Egyptian women from undergoing breast screening is lack of awareness of breast cancer and the importance of screening in early diagnosis.

In a previous study we demonstrated that Egyptian women take on average 4.4 months (131 days) from the time they develop a breast symptom until presentation. There is another lag from the time they see a health professional until they commence the appropriate treatment whether systemic, surgery or radiotherapy ${ }^{7}$. This lag time is variable according to the type of health care provider (private sector vs. public) and health care professional (gynaecologist vs. surgeon vs. oncologist). In most cases the time taken from developing symptoms until commencing treatment is more than 6 months, which is enough time for breast cancer to progress and upstage.

As patients contribute to the bigger part of the delay, we wanted to understand the rationale and causes behind this attitude by studying breast cancer perception and awareness of the disease and its risk factors. The authors also wanted to see if having a family member diagnosed with breast cancer would change breast cancer awareness among caregivers and if this would influence their future attitude and willingness to undergo screening.

\section{Methods}

\section{Study design and population}

The study was carried between August and November 2017. It included 704 women aged 17 or older. We studied two groups, non-caregivers and caregivers.

The "non-caregivers" group included 248 women representing the general population. This group was picked in a random manner from attendants at Ain Shams University hospital out-patient ophthalmology and physical medicine clinics. Noncaregivers were women coming to receive a service or family member attending with a patient.
The "caregivers" group comprised 456 female caregivers of breast cancer patients attending to a dedicated breast cancer centre in Cairo (Baheya Breast Cancer Centre) for investigations or treatment for breast cancer. Caregivers were either first- or second-degree relatives.

\section{Data Collection}

The study was conducted as a face-to-face interview with candidates via three final year medical students who were trained on the questionnaire, consenting and explaining to candidates the purpose of the study and giving them the liberty to refuse participation or withdraw at any time.

We used version 2 of the Breast Cancer Awareness Measure (Breast CAM) ${ }^{8}$. This was modified and some questions were added to fit the local culture and the purpose of the study. The questionnaire was translated into Arabic language by a bilingual expert and the translated version was then reversed back to English and approved by a validated translator to ensure accuracy (ForwardBackward method). We asked 18 women to complete our questionnaire as a pilot study and some modifications were carried accordingly. Cronbach's Alpha test was used to test reliability and this was 0.8. Time needed to complete the interview was 25 to 30 minutes in average. The questionnaire comprised 6 socio-demographic questions, a question on current breast symptoms if any, and 39 questions divided into four domains as follows:

$1^{\text {st }}$ domain (individual risk factors): 9 questions asking about menarche, menopause, pregnancy and family history of cancer.

$2^{\text {nd }}$ domain (awareness of breast cancer risk factors): 12 questions, starting with a general question asking about whether the candidate is aware of factors that might increase women's potential risk of breast cancer going through specific risk factors - internal and external- like age, overweight, breast density, positive family history and hormone therapy.

$3^{\text {rd }}$ domain (awareness of breast cancer screening): 11 questions to examine candidates' knowledge on breast screening methods, time, frequency and if they believe screening improves outcomes.

$4^{\text {th }}$ domain (current behaviour, barriers to screening and future intention): Candidates were asked whether they had previous breast 
imaging, BRCA testing or done BSE and what might be possible obstacles against breast screening. The survey closed with 3 questions asking if the candidate is willing to practice BSE and/or screening.

A paper form was used to collect responses which were then pooled into a master datasheet. Responses were coded for statistical analysis. Data was analysed for each group separately then was compared to the other group.

For the purpose of this study, giving correct answers for more than half of the questionnaire questions was considered good knowledge of breast cancer. So, we used $50 \%$ score of right answers as a cutoff to categorize the study candidates into good vs. poor knowledge.

\section{Statistical analysis}

Numerical data were summarized as mean + standard deviation (SD) or median + range as appropriate while categorical data were summarized as frequency and percentage. Analysis comparing numerical data between the two groups were done using Student's $t$-test for independent samples while comparisons of categorical data were done using Chi-square test. Regarding demographic and clinical characteristics, missing data were not included in the analysis while regarding awareness missing data were considered lack of awareness. The correct answers were summed to get the participants' score and those who answered more than $50 \%$ of the questions correctly were considered to have good knowledge. Multivariate regression model was done to adjust for the significance between groups in demographic data. Pearson's correlation was used for correlation between the percent overall score and numerical and dichotomous data while Eta2 was calculated for categorical data with more than 2 levels. All statistical tests were two-sided and $p$ value $<0.05$ was considered significant. The analysis was done using IBM SPSS Statistics for Windows, Version 27.0. (Armonk, NY: IBM Corp).

\section{Ethical considerations}

This study was performed in line with the principles of the Declaration of Helsinki. Approval was granted by the Clinical Research Ethics Committee of Baheya Foundation for Breast Cancer on 28-June-2017 (Approval No. 0317/2017). The study aims were explained, written information was handed and informed consent was obtained from all participants.

\section{Results}

\section{Demographic and clinical data}

The mean age of all participant was 39.92 years ranging from 17 to 86 years old. Around $73 \%$ of the them were premenopausal and $78 \%$ of them were married. There were significant differences between the two groups regarding, age, menopausal status, marital status, and educational level. These data are summarized in Table 1.

The most common reported warning sign of breast cancer was pain in both groups but caregivers reported significantly higher rates of breast mass, axillary mass, and pain compared to non-caregivers as summarized in Table 2.

\section{Awareness of risk factors for breast cancer}

When asked about risk factors for breast cancer, the percentage of participant that correctly answered risk factors questions among noncaregivers vs. caregivers were as follows; older age $(23.5 \%$ vs. $35.8 \%)$, family history $(36 \%$ vs. $56 \%)$, benign breast disease ( $30 \%$ vs. $43.8 \%$ ), radiation exposure ( $10 \%$ vs. $23 \%)$, increased breast density (6\% vs. $20.6 \%)$, obesity $(27 \%$ vs. $37 \%)$, early menarche (5\% vs. $11.1 \%)$, oral contraceptive pills ( $20 \%$ vs. $50 \%$ ) and late menopause (6.5\% vs. $13.7 \%)$. Among participants, $56.2 \%$ knew that lactation is protective while $59.1 \%$ knew that breast cancer can be asymptomatic. Overall, $18.1 \%$ of non-caregivers were reported to have good knowledge about risk factors of breast cancer compared to $38.3 \%$ of caregivers (Table 3).

\section{Awareness of breast cancer screening method and early detection}

Caregivers demonstrated better knowledge of breast cancer screening than non-caregivers. More than $80 \%$ of non-caregivers were considered to have poor knowledge of the methods for breast cancer screening as represented in Table 3.

Seventy-two percent of caregivers vs. $44 \%$ of non-caregivers were aware that breast cancer can be early detected and $91.7 \%$ vs. $68.5 \%$ reported that screening can improve outcomes and disease morbidity. Breast self-examination, CBE and mammogram were recognized as methods of early detection by $97 \%, 27 \%$ and $47.8 \%$ of caregivers compared to $23.4 \%, 1.6 \%$ and less than $1 \%$ of noncaregivers, respectively. 
Table 1: Socio-demographic data of participants

\begin{tabular}{|c|c|c|c|c|}
\hline \multirow[t]{2}{*}{ Parameter } & & \multirow{2}{*}{$\begin{array}{l}\text { Non-caregivers } \\
\text { Mean (SD) }\end{array}$} & \multicolumn{2}{|l|}{ Caregivers } \\
\hline & & & Mean (SD) & $p$ value $*$ \\
\hline Age $^{a}$ & & $43.2(15.7)$ & 38.09 (13) & $<0.001$ \\
\hline Age at $1^{\text {st }}$ menstruation ${ }^{b}$ & & $13.2(1.6)$ & $13.35(1.5)$ & 0.365 \\
\hline \multirow[t]{2}{*}{ Age at $1^{\text {st }}$ pregnancy ${ }^{c}$} & & $21.1(3.6)$ & $22.58(3.9)$ & $<0.001$ \\
\hline & & $n(\%)$ & $n(\%)$ & $p$ value ${ }^{* *}$ \\
\hline \multirow{2}{*}{ Menopausal status } & Premenopausal & $164(66.4)$ & $352(77.5)$ & 0.002 \\
\hline & Postmenopausal & $83(33.6)$ & $102(22.5)$ & \\
\hline \multirow[t]{2}{*}{ Marital status } & Yes & $210(85.5)$ & $336(74)$ & 0.001 \\
\hline & No & $36(14.6)$ & $118(26)$ & \\
\hline \multirow[t]{2}{*}{ Current pregnancy } & Yes & $14(5.7)$ & $23(5.1)$ & 0.715 \\
\hline & No & $231(94.3)$ & 431 (94.9) & \\
\hline \multirow[t]{2}{*}{ Current lactation } & Yes & $12(4.9)$ & $16(3.5)$ & 0.38 \\
\hline & No & $233(95.1)$ & 437 (96.5) & \\
\hline \multirow[t]{2}{*}{ Family history of ovarian cancer } & Yes & $15(6)$ & $26(5.7)$ & 0.851 \\
\hline & No & $233(94)$ & $430(94.3)$ & \\
\hline \multirow[t]{6}{*}{ Educational level } & No education & $99(40.1)$ & $54(11.9)$ & $<0.001$ \\
\hline & Primary & 27 (10.9) & $21(4.6)$ & \\
\hline & Preparatory & $28(11.3)$ & $32(7)$ & \\
\hline & High school & $55(22.3)$ & $124(27.3)$ & \\
\hline & Junior college & $20(8.1)$ & $71(15.6)$ & \\
\hline & Regular college & $18(7.3)$ & $152(33.5)$ & \\
\hline
\end{tabular}

${ }^{\mathrm{a}} n=246$ non-caregivers and 444 caregivers, ${ }^{\mathrm{b}} n=161$ non-caregivers and 418 caregivers, ${ }^{\mathrm{c}} \mathrm{n}=247$ non-caregivers and 454 caregivers;

* Student $t$-test, ${ }^{* *}$ Chi-square test

Table 2: Frequency of warning signs of breast cancer reported by non-caregivers and caregivers

\begin{tabular}{llll}
\hline Parameter & & Non-caregivers & Caregivers \\
\cline { 2 - 4 } & & $\boldsymbol{n}(\%)$ & $\boldsymbol{n}(\%)$ \\
\hline \multirow{2}{*}{ Breast mass } & Yes & $3(1.2)$ & $31(6.8)$ \\
\cline { 2 - 4 } & No & $244(98.8)$ & $425(93.2)$ \\
\hline Discharge & Yes & $12(4.9)$ & $24(5.3)$ \\
\cline { 2 - 4 } & No & $235(95.1)$ & $432(94.7)$ \\
\hline Pain & Yes & $22(8.9)$ & $98(21.5)$ \\
\cline { 2 - 4 } & No & $225(91.1)$ & $358(78.5)$ \\
\hline Axillary mass & Yes & $7(2.8)$ & $33(7.2)$ \\
\cline { 2 - 4 } & No & $240(97.2)$ & $423(92.8)$ \\
\hline Skin change & Yes & $1(0.4)$ & $11(2.4)$ \\
\cline { 2 - 4 } & No & $246(99.6)$ & $445(97.6)$ \\
\hline
\end{tabular}

*Chi-square test

Table 3: Comparison of knowledge between non-caregivers and caregivers

\begin{tabular}{|c|c|c|c|c|}
\hline \multirow[t]{2}{*}{ Parameter } & & \multirow{2}{*}{$\begin{array}{l}\text { Non-caregivers } \\
n(\%)\end{array}$} & \multirow{2}{*}{$\begin{array}{l}\text { Caregivers } \\
n(\%)\end{array}$} & \multirow[t]{2}{*}{$p$ value* } \\
\hline & & & & \\
\hline \multirow[t]{2}{*}{ Awareness of breast cancer risk factors } & Good knowledge & $45(18.1)$ & $173(38.3)$ & \multirow[t]{2}{*}{$<0.001$} \\
\hline & Poor knowledge & $203(81.9)$ & $279(61.7)$ & \\
\hline \multirow[t]{2}{*}{ Awareness of breast cancer screening } & Good knowledge & $44(14.7)$ & $298(65.4)$ & \multirow[t]{2}{*}{$<0.001$} \\
\hline & Poor knowledge & $204(82.3)$ & $158(34.6)$ & \\
\hline \multirow[t]{2}{*}{ Overall knowledge } & Good knowledge & $32(12.9)$ & $201(44.1)$ & \multirow[t]{2}{*}{$<0.001$} \\
\hline & Poor knowledge & $216(87.1)$ & 255 (55.9) & \\
\hline
\end{tabular}


When asked about BSE, $41 \%$ of the whole study group knew that it should be done with fingers and only $27.6 \%$ of caregivers and $11 \%$ of non-caregivers knew that it should be done monthly.

Television, radio and social media were the main sources of information on breast cancer screening for study participants in both groups (51\%) followed by friends (16\%) and family members (5\%).

Regarding previous screening, $18.6 \%$ of caregivers had previous imaging and $38.1 \%$ performed BSE compared to $2.8 \%$ and $11.3 \%$ of non-caregivers, respectively.

\section{Overall assessment of knowledge}

The median (range) overall percent score for non-caregivers was $23.8 \% \quad(0-85.7)$ while for caregivers it was $47.6 \%(0-100)(p<0.001)$.

When running a multivariate regression model with age, menopausal status, marital status, and educational level only educational level had a significant impact on the overall percent score by $56 \%(p<0.001)$. After applying the regression model on each group, also the educational level was found to be affecting the overall percent score by $45 \%$ ( $p$ $<0.001)$ in non-caregivers and $46 \%(p<0.001)$ in caregivers. It was found that the educational level affected the overall percent score nearly the same in both groups. Hence, the initial baseline difference might be due to chance or different sample size in each group. These data are summarized in Table 4.

We noticed that there was a significantly higher rate of college and high school education among caregivers than non-caregivers $(76 \%$ vs. $38 \%$, respectively), so we wanted to investigate whether the notable difference in breast cancer knowledge is attributed only to the difference in the level of education between the two groups hence we performed a comparison between the two groups based on educational level stratifying each group into higher education vs. lower education where the higher education group included those who received high school or college education and lower education are those who did not.

There were still remarkable differences between the two groups as shown in Table 5. In the High education group, $24 \%$ of non-caregivers demonstrated good knowledge vs. $53 \%$ of caregivers $(p<0.001)$. In the low education group, the percentages were $6.5 \%$ and $14.8 \%$ respectively. The differences were statistically significant.

\section{Current behaviour, future intention, and obstacles to screening}

Overall, $12.9 \%$ of the participants reported previous breast imaging while $28.6 \%$ reported previous BSE. Caregivers of breast cancer patients showed significant higher reporting of previous BSE and imaging compared to non-caregivers.

More than $65 \%$ of the participants reported they have the intention to perform BSE, CBE and mammography. This data is summarized in Table 6. Several obstacles to breast cancer screening were described by the participants including unawareness of its benefit (46.1\%), fear to discover cancer (35.5\%), financial obstacles (14.3\%), and others (12.3\%).

\section{Discussion}

Breast cancer is the most common type of cancer in Egyptian women and although incidence rates are not as high as in the west, yet breast cancer mortality is considerably worse ${ }^{9}$.

A major cause in low- and middle-income countries is late stage presentation and Egypt is not an exception ${ }^{10}$. There is limited access to sophisticated technologies and targeted therapies in the public sector and prioritizing investing into early detection and diagnosis at an early stage is indeed more practical and cost-effective measure to improve disease survival and reduce mortality. The result of the United Kingdom national breast screening programme is a good example of how down staging breast cancer presentation via early detection and screening can improve cure rates ${ }^{11}$.

Lack of awareness of different aspects of breast cancer was demonstrated in our study. In terms of risk factors, more than two thirds (68.9\%) of study participants showed poor knowledge. Least recognized risk factors were early menarche and late menopause. While most recognized risk factors were positive family history and oral contraceptive pills. Most did not know that overweight can increase the risk of breast cancer (only 33\% did). This is of particular concern as Egypt is among top countries in the world in terms of overweight and obesity with prevalence ranging from $74-86 \%$ among females according to the WHO ${ }^{12}$ hence more effort is needed to increase awareness on obesity related morbidities including cancer in general and breast cancer in particular.

As regards screening awareness, caregivers of breast cancer patients demonstrated better awareness with $65 \%$ having a good level of 
Table 4: Regression model with percent overall score as the outcome

\begin{tabular}{lllllll}
\hline Variable & \multicolumn{2}{l}{ All participants } & \multicolumn{2}{l}{ Non-caregivers } & \multicolumn{2}{l}{ Caregivers } \\
\cline { 2 - 9 } & Beta & $\boldsymbol{p}$ value & Beta & $\boldsymbol{p}$ value & Beta & $\boldsymbol{p}$ value \\
\hline Age & -0.034 & 0.512 & -0.053 & 0.583 & -0.041 & 0.545 \\
\hline Menopausal status & -0.027 & 0.563 & -0.07 & 0.415 & -0.015 & 0.797 \\
\hline Marital status & -0.038 & 0.294 & -0.078 & 0.211 & -0.026 & 0.613 \\
\hline Educational levels & 0.562 & $<0.001$ & 0.451 & $<0.001$ & 0.461 & $<0.001$ \\
\hline
\end{tabular}

Table 5: Comparing overall knowledge between non-caregivers and caregivers according to education level

\begin{tabular}{lllll}
\hline Parameter & & Non-caregivers & Caregivers & \multirow{2}{*}{$\boldsymbol{p}$ value } \\
\cline { 2 - 4 } & & $\boldsymbol{n}(\%)$ & $\boldsymbol{n}(\%)$ & \\
\hline Higher educational level ( $\geq$ high school) & Good knowledge & $22(23.7)$ & $184(53.2)$ & $<0.001$ \\
\cline { 2 - 4 } & Poor knowledge & $71(76.3)$ & $162(46.8)$ & \\
\hline Lower educational level (< high school) & Good knowledge & $10(6.5)$ & $16(14.8)$ & 0.027 \\
\cline { 2 - 4 } & Poor knowledge & $144(93.5)$ & $92(85.2)$ & \\
\hline
\end{tabular}

${ }^{*}$ Chi-square test

Table 6: Comparison of current behaviour and future intent to perform breast cancer screening between non-caregivers and caregivers

\begin{tabular}{|c|c|c|c|c|}
\hline \multirow[t]{2}{*}{ Parameter } & & \multirow{2}{*}{$\begin{array}{l}\text { Non-caregivers } \\
n(\%)\end{array}$} & \multirow{2}{*}{$\begin{array}{l}\text { Caregivers } \\
n(\%)\end{array}$} & \multirow[t]{2}{*}{$p$ value $*$} \\
\hline & & & & \\
\hline \multirow[t]{2}{*}{ Previous imaging } & Yes & $7(2.8)$ & $83(18.6)$ & $<0.001$ \\
\hline & No & $241(97.2)$ & $36(81.4)$ & \\
\hline \multirow[t]{2}{*}{ Previous breast-self examination } & Yes & $28(11.4)$ & $169(38.2)$ & $<0.001$ \\
\hline & No & $218(88.6)$ & $273(61.8)$ & \\
\hline \multirow[t]{3}{*}{ Intention to breast-self examination } & Yes & $204(82.3)$ & $377(82.7)$ & 0.62 \\
\hline & No & $40(16.1)$ & $67(14.7)$ & \\
\hline & I don't know & $4(1.6)$ & $12(2.6)$ & \\
\hline \multirow[t]{3}{*}{ Intention to clinical breast examination } & Yes & $172(69.4)$ & $323(70.8)$ & 0.579 \\
\hline & No & $71(28.6)$ & $119(26.1)$ & \\
\hline & I don't know & $5(2)$ & $14(3.1)$ & \\
\hline \multirow[t]{3}{*}{ Intention to mammogram } & Yes & $168(67.7)$ & $311(68.2)$ & 0.698 \\
\hline & No & $70(28.2)$ & $132(28.9)$ & \\
\hline & I don't know & $10(4)$ & $13(2.9)$ & \\
\hline
\end{tabular}

*Chi-square test

knowledge. Most of this group knew benefits of early detection and that screening can improve outcomes including morbidity and mortality. Yet they showed deficient knowledge in methods of screening, frequency, age and how to perform BSE. On the other hand, the vast majority of noncaregivers (82.3\%) showed poor screening knowledge. Only 44\% of study participants scored more than $50 \%$ indicating defective knowledge in the screening domain.

The cumulative overall percent score reflects total knowledge in all aspects of the survey. On the whole, the overall assessment showed poor knowledge in both groups. Caregivers despite attaining significantly higher scores in all domains particularly in screening section yet their overall score was still less than 50\%. Non-caregivers showed marked lack of overall knowledge with almost 9 out of 10 candidates failing to score beyond $50 \%$. The overall better knowledge of breast cancer amongst caregivers could have impacted their awareness of their breasts and therefore explain the notably higher reported symptoms of breast mass, axillary mass, and mastalgia compared to non-caregivers.

Higher education was associated with better knowledge in our study and the effect was confirmed by correlation and regression analyses which were highly statistically significant. This was also observed and reported in other studies ${ }^{13}, 14$. The level of education had the same effect in both groups and because the level of education was 
remarkably higher in caregivers this indeed could have been a key factor for the higher scores in the level of knowledge and awareness in favour of caregivers. Nevertheless, this was not the only factor as a cross-comparison of responses among participants at the same level of education in both groups showed again higher scores and better knowledge among caregivers which indicates an effect of being a caregiver to a breast cancer patient. The effect of having a family member diagnosed with breast cancer on disease awareness was also a notable finding reported in several other studies ${ }^{14-17}$.

In terms of behaviour, the rates of screening in our study were higher than those seen in the 2015 DHS report. Rates of imaging were $18.6 \%$ in caregivers and $2.8 \%$ in non-caregivers while rates of BSE were $38.1 \%$ in caregivers and $11.3 \%$ in noncaregivers. In the Demographic and Health Survey report, only $1.5 \%$ were screened radiologically and $6.2 \%$ conducted BSE. These are almost half of the figures noticed in non-caregivers of our study. The substantial better practice observed in caregivers could be the effect of higher rates of education and having a family member diagnosed with the disease.

It is worth noting that the age of women in the Demographic and Health Survey report (range 15 59 years) and in our study (mean = 39 years) was relatively young and large numbers of these women would not have been eligible for screening by age criteria.

Fear to discover cancer and unawareness of the importance of early detection were the main barriers to seek screening. There is a great need to raise public understanding of the disease highlighting the fact that early diagnosis is associated with higher cure rates and shortening treatment journey. Our study showed that television and media in general were the most influential source of information therefore these should be utilized as key tools in awareness campaigns.

The limitations in this study include involving women residing in Cairo only so does not necessarily reflect level of knowledge among all Egyptians. The two groups were not balanced and level of education was significantly higher in caregivers as aforementioned which contributed to the better scores observed in this group.

\section{Conclusion}

Breast cancer knowledge among Egyptian women is deficient. Better education and family history of breast cancer significantly affect the level of knowledge and attitude towards screening. There is a need to defy the fear of the disease and breast cancer stigma via the implementation of a national awareness program where television and social media can be valuable tools.

\section{Acknowledgment \\ None. \\ Authors' contribution \\ Conception or design: AHA, MKJ; Acquisition, analysis or interpretation of data: All authors; Drafting the manuscript or revising it: All authors; Approval of the manuscript version to be published: All authors; Agreement to be accountable for all aspects of the work: All authors.}

\section{Conflict of interest}

The authors declare that they have no conflict of interest to disclose.

\section{Data availability}

Deidentified individual participant data used to produce the results of this study are available from the corresponding author (AHA) upon request.

\section{Funding}

This research did not receive any specific grant from funding agencies in the public, commercial, or not-for-profit sectors

\section{Study registration}

None.

\section{References}

1. Bray F, Ferlay J, Soerjomataram I, Siegel RL, Torre LA, Jemal A. Global cancer statistics 2018: GLOBOCAN estimates of incidence and mortality worldwide for 36 cancers in 185 countries. CA Cancer J Clin. 2018; 68(6): 394-424.

2. Ibrahim AS, Khaled HM, Mikhail NN, Baraka H, Kamel H. Cancer incidence in Egypt: Results of the National Population-Based Cancer Registry Program. J Cancer Epidemiol. 2014; 2014: 437971.

3. Abd Aziz KK, Tawfik EA, Shaltout EA, Abdel Moneum RA. Clinical outcome and survival of breast cancer patients treated at the Clinical Oncology Department, Menoufia University. Menoufia Med J. 2015; 28(2): 333-339.

4. Farouk O, Ebrahim MA, Senbel A, et al. Breast cancer characteristics in very young Egyptian women $\leq 35$ years. Breast Cancer (Dove Med Press). 2016; 8: 5358.

5. El Saghir NS, Khalil MK, Eid T, et al. Trends in epidemiology and management of breast cancer in developing Arab countries: a literature and registry analysis. Int J Surg. 2007; 5: 225-233.

6. Ministry of Health and Population [Egypt], El-Zanaty and Associates [Egypt], and ICF International. 2015. 
Egypt Health Issues Survey 2015. Cairo, Egypt and Rockville, Maryland, USA: Ministry of Health and Population and ICF International.

7. Abdelaziz AH, Abdou AM, Habeeb CN. Breast cancer treatment waiting time, patient and provider contributions: An Egyptian breast cancer centre experience. Ann Oncol. 2018: 29(Suppl 8): VIII566.

8. Cancer Research United Kingdom, University College London, Kings College London and Oxford University. Breast cancer Awareness Measure (Breast CAM) version 2.1. 2009. Available from: http://reshare.ukdataservice.ac.uk/851845/37/BreastC AM.pdf. Last accessed: 30-May-2020.

9. Global Burden of Disease Cancer Collaboration; Fitzmaurice C, Abate D, Abbasi N, et al. Global, regional, and national cancer incidence, mortality, years of life lost, years lived with disability, and disability-adjusted life-years for 29 cancer groups, 1990 to 2017: A systematic analysis for the Global Burden of Disease Study. JAMA Oncol. 2019; 5(12): 1749-1768.

10. WHO Cancer factsheet. 2018. Available from: http://www.who.int/mediacentre/factsheets/fs297/en/ . Last accessed: 26-May-2020.

11. Stockton D, Davies T, Day N, McCann J. Retrospective study of reasons for improved survival in patients with breast cancer in East Anglia: Earlier diagnosis or better treatment. BMJ. 314(7079): 472-475.
12. World Health Organization. Framework for the implementation of the global strategy on diet, physical activity and health in the Eastern Mediterranean Region. 2010. Available from: https://applications.emro.who.int/dsaf/emropub 201 0 1273.pdf. Last accessed: 26-May-2020.

13. Radi SM. Breast Cancer awareness among Saudi females in Jeddah. Asian Pac J Cancer Prev. 2013; 14(7): 4307-4312.

14. Liu LY, Wang F, Yu LX, et al. Breast cancer awareness among women in Eastern China: a crosssectional study. BMC Public Health. 2014; 14: 1004.

15. Erbil N, Bölükbaş N. Beliefs, attitudes, and behavior of Turkish women about breast cancer and breast self-examination according to a Turkish version of the Champion Health Belief Model Scale. Asian Pac J Canc Prev. 2012; 13(11): 5823-5828.

16. Tastan S, Iyigün E, Kilic A, Unver V. Health beliefs concerning breast self-examination of nurses in Turkey. Asian Nursing Res (Korean Soc Nurs Sci). 2011; 5(3): 151-156.

17. Dündar PE, Ozmen D, Oztürk B, et al. The knowledge and attitudes of breast self-examination and mammography in a group of women in a rural area in western Turkey. BMC Cancer. 2006; 6: 43. 